\title{
Selective Formation and Modulation of Electrical Synapses Between Cultured Aplysia Neurons
}

\author{
Grant M. Carrow and Irwin B. Levitan \\ Graduate Department of Biochemistry, Brandeis University, Waltham, Massachusetts 02254
}

\begin{abstract}
When dissociated neurons from the mollusc, Aplysia californica, are placed in primary cell culture, they form electrical synapses in a specific, yet alterable, manner. Pairs of neurons from the same ganglion ("homoganglionic" pairs) form electrical synapses with high coupling coefficients. This is due to relatively high macroscopic junctional conductance as determined directly by voltage clamping both neurons of each pair. By contrast, synapses between pairs of neurons from different ganglia ("heteroganglionic" pairs) exhibit lower coupling coefficients as a result of lower macroscopic junctional conductance. Both types of junction are nonrectifying, not gated by voltage, and resistant to uncoupling by octanol and heptanol.

This dichotomy of synaptic efficacy is altered upon exposure of the neurons to the lectin, conacanavalin A (Con A). Acute treatment of heteroganglionic cell pairs with Con A increases their junctional conductance to the higher level characteristic of homoganglionic pairs within several hours. However, the higher junctional conductance of homoganglionic pairs is not modulated by Con A. The results presented here suggest that synaptic specificity among these regenerating neurons may be mediated at least in part by ganglion-specific cell-recognition molecules. Furthermore, these molecules may be, or may be linked to, lectin receptors that regulate gap junction channels.
\end{abstract}

The pattern of connections between cells of the nervous system is the end product of a series of developmental processes beginning with axon outgrowth and guidance toward a target and proceeding through the formation of specific synapses. Once established this circuitry is not static, however, since connections may be altered, added, or abolished with time. In all stages of neural circuit assembly and fine tuning, from process outgrowth through synapse modification, cell surface molecules appear to be involved in mediating cellular interactions. Thus, neurite outgrowth (usually assayed in vitro) is promoted by several classes of proteins, including endogenous neurotrophic factors, growth-promoting molecules, and extracellular matrix proteins (Thoenen and Edgar, 1985; Jessell, 1988), as well as exogenous lectins (DeGeorge et al., 1985; Chiquet and Acklin, 1986; Lin and Levitan, 1987), presumably all acting via specific

\footnotetext{
Received Dec. 28, 1988; revised Mar. 23, 1989; accepted Apr. 13, 1989.

We thank D. Dagan, S. Lin, J. Lisman, and D. Spray for comments. This research was supported by NIH grant NS25366 to I.B.L. and NRSA Fellowship F32HD06739 to G.M.C.

Correspondence should be addressed to Dr. Grant M. Carrow at the above address.

Copyright (c) 1989 Society for Neuroscience $0270-6474 / 89 / 103657-08 \$ 02.00 / 0$
}

receptors. Pathfinding by growth cones and axon fasciculation depend upon axonal pathways with differentially expressed cell surface proteins (Goodman et al., 1982; McKay et al., 1983; Jessell, 1988), as well as neural cell-adhesion molecules (Edelman, 1986; Jessell, 1988; Rutishauser et al., 1988). Finally, voltage-sensitive and chemosensitive membrane ion channels are modulated by a broad spectrum of factors to bring about changes in synaptic connectivity (Kandel and Schwartz, 1982; Cotman and Monaghan, 1988; Levitan, 1988; Nicoll et al., 1988).

While a number of cell surface molecules appear to be involved in the cell-cell recognition required for axon pathfinding and fasciculation, it is not clear that the same molecules mediate the recognition required for the formation of specific synapses. In many cases, sets of similar neurons that synapse on the same target cell still demonstrate specific differences in the type or strength of synapses formed (Scott and Mendell, 1976; Nja and Purves, 1977; Fuchs et al., 1981; Bodmer et al., 1984; Lichtman and Frank, 1984; Arechiga et al., 1986). This spccificity of ccllular interaction during synaptogenesis may be mediated by mechanisms distinct from those used at other stages of nervous system assembly.

Because the sites of synaptic connections often are not readily accessible to experimental manipulation in neural tissue, cell culture provides a more tractable means of investigating the processes involved in synaptogenesis. Neurons grown in primary culture after dissociation often exhibit selectivity in the formation of both chemical and electrical synapses (Fuchs et al., 1981; Camardo et al., 1983; Bodmer et al., 1984; Arechiga et al., 1986; Rayport and Schacher, 1986; Haydon, 1988). In particular, cultured neurons from the CNS of the marine mollusc, Aplysia californica, provide a promising model for the study of synaptic specificity and plasticity. For example, neurons from the bag cell clusters of the abdominal ganglion readily form electrical synapses with each other in vitro (Kaczmarek et al., 1979), as do neurons from the buccal ganglion (Dagan and Levitan, 1981). However, despite the competence of each of these cell types to form strong electrical connections, no coupling was detected between bag cells and buccal cells in mixed culture (Bodmer et al., 1984; Lin and Levitan, 1987). By contrast, when these cells were grown in the continued presence of the lectin concanavalin A (Con A), buccal-bag electrical synapses were observed (Lin and Levitan, 1987). These findings suggest that Aplysia electrical synapses in vitro are specific and plastic. The combination of predictable patterns of connectivity, a ligand that alters connectivity, and accessibility of the neurons to biochemical and physiological analysis suggests that this simple system may provide an opportunity to gain insights into the mechanisms involved in cell-cell recognition, synaptogenesis, and synaptic regulation. 
In the present work, we investigated the extent and mechanism of synaptic specificity among cultured neurons from the CNS of Aplysia, as well as the mode of action of Con A in altering connectivity. We have found that pairs of neurons from the several ganglia, grown in a completely defined medium without Con $\mathrm{A}$, readily form electrical synapses in all combinations tested. Nevertheless, there does exist synaptic specificity in vitro that is detectable as a difference in efficacy of the electrical synapses formed. This difference depends on the ganglionic origin of the neurons and is quantifiable by measurement of the macroscopic junctional conductance between neurons. Moreover, we have found that Con A alters connectivity by modulating the junctional conductance of previously established synapses. A preliminary report of these findings has appeared (Carrow and Levitan, 1987).

\section{Materials and Methods}

Juvenile Aplysia weighing 3-8 gm were obtained from the Aplysia Resource Facility of the Howard Hughes Medical Institute (Woods Hole, MA) and maintained in artificial seawater at $16^{\circ} \mathrm{C}$. Primary culture of neurons was achieved by modification of established procedures (Dagan and Levitan, 1981; Schacher and Proshansky, 1983). The nervous system sheath was enzymatically digested by incubating ganglia in medium with neutral protease (1.0-1.5\%; Boehringer Mannheim), $\mathrm{pH} 7.4$ at $34^{\circ} \mathrm{C}$ for 3-4 hr. The incubation medium consisted of L-15 medium (KC Biological or Flow Laboratories) buffered to $\mathrm{pH} 7.7$ with $10 \mathrm{~mm}$ HEPES and to which was added $320.4 \mathrm{mM} \mathrm{NaCl}, 4.6 \mathrm{~mm} \mathrm{KCl}, 9.7 \mathrm{~mm} \mathrm{CaCl}_{2}$, $53.2 \mathrm{mM} \mathrm{MgCl}, 56 \mathrm{~mm}$ glucose, 100 units $/ \mathrm{ml}$ penicillin, $100 \mu \mathrm{g} / \mathrm{ml}$ streptomycin, and $250 \mathrm{ng} / \mathrm{ml}$ amphotericin B. Ganglia were washed in fresh incubation medium, desheathed, and the neurons were dissociated frec of the ganglia with firc-polished glass needles. Cells were then transferred by pipette onto an uncoated, glass coverslip in culture medium consisting of the incubation medium with added methylcellulose $(1 \%$, Sigma) and, in some cases, $25 \%$ Aplysia hemolymph. The coupling between cells grown in the presence of hemolymph was not detectably different than that between cells grown in a completely defined medium so that the data are pooled here. Plated neurons were maintained at 19 or $22^{\circ} \mathrm{C}$, and half the medium was replaced with fresh medium every 3-4 d. Neurons were used for experiments between 3 and $10 \mathrm{~d}$ after plating.

For electrophysiological recording, coverslips with adhering cells were placed in a chamber perfused $(0.5-1.0 \mathrm{ml} / \mathrm{min})$ with saline: $460 \mathrm{mM}$ $\mathrm{NaCl}, 10 \mathrm{mM} \mathrm{KCl}, 11 \mathrm{~mm} \mathrm{CaCl}_{2}, 55 \mathrm{mM} \mathrm{MgCl}, 10 \mu \mathrm{M} \mathrm{MnCl}_{2}, 56 \mathrm{~mm}$ glucose, 20 units $/ \mathrm{ml}$ penicillin, $20 \mu \mathrm{g} / \mathrm{ml}$ streptomycin, $50 \mathrm{ng} / \mathrm{ml} \mathrm{am-}$ photericin $\mathrm{B}$, and $10 \mathrm{~mm}$ HEPES, $\mathrm{pH}$ 7.7. Each neuron was penetrated with a single microelectrode filled with $0.5 \mathrm{M} \mathrm{K}_{2} \mathrm{SO}_{4}$ and $0.15 \mathrm{M} \mathrm{KCl}$, 5-10 M . Current clamping or voltage clamping was accomplished by rapidly switching (1-2 kHz) between current injection and voltage monitoring. Any neuron pairs in which each cell could not be simultaneously and independently voltage-clamped were not considered further. Con A (Sigma, type V) and L-glutamate were dissolved in saline. Octanol and heptanol were dissolved in dimethyl sulfoxide (DMSO, final concentration $<0.1 \%$ ) prior to addition to saline. The L-glutamate was applied by pressure ejection through a glass pipette with an orifice less than $5 \mu \mathrm{m}$ and placed within $30 \mu \mathrm{m}$ of the cell surface. The results reported are based on at least 4 replicates for each experiment.

\section{Results}

\section{Selective formation of electrical synapses}

In order to investigate specificity in the formation of electrical synapses among Aplysia neurons, we placed various combinations of cells in primary culture. Neurons from the abdominal, buccal, cerebral, pedal, and pleural ganglia as well as the bag cell clusters were paired with others from the same ganglion or cluster ("homoganglionic" pairs), or neurons from different ganglia were paired in mixed cultures ("heteroganglionic" pairs). The neurons were plated with their somata either directly apposed or separated by $50-300 \mu \mathrm{m}$. After allowing the cells to regenerate neurites, the coupling coefficient between cells of a pair was determined by current-clamping the cells, and the junctional conductance was calculated indirectly from current-clamp records as well as measured directly by simultaneously voltage clamping both cells of the pair (Bennett, 1966; Bodmer et al., 1988). In either case, both cells were clamped at the same potential, and current or voltage steps or ramps were applied to one member of the pair. Figure 1 and Table 1 show that among the pairs of cells that are electrically coupled, the magnitude of coupling differs between homoganglionic and heteroganglionic pairs. Thus, homoganglionic pairs are coupled with high coupling coefficients (ranging up to 0.95), reflecting junctional conductances $\left(G_{j}\right)$ usually in the range of $10-25 \mathrm{nS}$, and occasionally higher; often, an action potential generated in the presynaptic (current injected) cell evokes an action potential in the postsynaptic (follower) cell (Fig. $1 \mathrm{~A}$ ). By contrast, heteroganglionic pairs are coupled with lower coupling coefficients ( 0.25 or less), due to $G_{j}$ less than $5 \mathrm{nS}$; presynaptic action potentials often evoke postsynaptic electrotonic potentials, but they are of insufficient magnitude to evoke action potentials in the postsynaptic cell (Fig. $1 B$ ).

This dichotomy of synaptic strength between homoganglionic and heteroganglionic cell pairs was observed for different combinations of cells from the various ganglia; while not all possible heteroganglionic combinations of cells were tested, the results were consistent for those combinations that were examined. Synapses between pairs of buccal neurons and bag cells, as shown in Fig. $1 C$, are characteristic of those of other heteroganglionic pairs. Previously, buccal-bag electrical synapses had not been detected in vitro when the cells were grown in a standard culture medium containing fetal calf serum (Bodmer et al., 1984; Lin and Levitan, 1987). However, we have now found that culturing of these neurons in serum-free medium, with or without hemolymph, reveals a relatively low (heteroganglionic) level of buccal-bag coupling. It has been observed that serum is capable of inhibiting electrical coupling between cultured sympathetic neurons (Higgins and Burton, 1982; Kessler et al., 1984), and this may be the case for Aplysia neurons as well. Indeed, buccalbag coupling was previously seen when the neurons were grown in the presence of Con A (Lin and Levitan, 1987), possibly because the lectin overcomes the inhibitory action of serum. The level of junctional conductance between coupled pairs of cells is independent of the configuration in which the cells are plated; that is, a given combination of cells, whether separated by $50-300 \mu \mathrm{m}$ or with cell somata apposed, shows the level of junctional conductance characteristic of that combination (see Fig. 1).

\section{Properties of homoganglionic and heteroganglionic synapses}

Most nonembryonic electrical synapses do not exhibit voltage gating or rectification. Similarly, electrical synapses between cultured buccal neurons from Aplysia have been shown to be voltage independent and nonrectifying (Bodmer et al., 1988). As indicated in Figure $2 B$, the junctions between other homoganglionic pairs also show no voltage gating since the $I-V$ curves are linear. Nor are these junctions rectifying since $G_{j}$ is constant, regardless of the member of a pair used for current injection or the sign of the current injected, as illustrated in Figure 2, $A, B$. Moreover, as shown in Figure $2 C$, heteroganglionic junctions are similarly voltage insensitive and nonrectifying. These data confirm the results of Bodmer et al. (1988) for buccal-buccal 
A
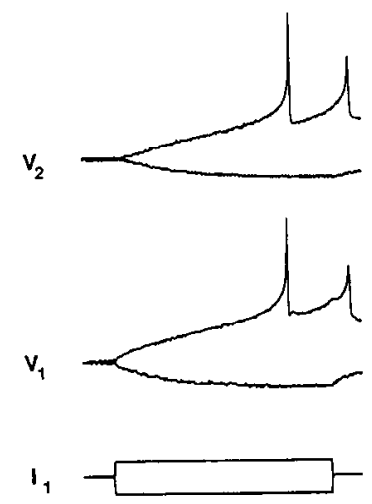

B
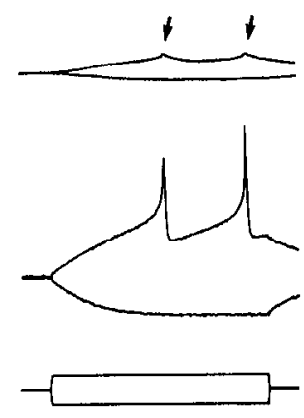

C

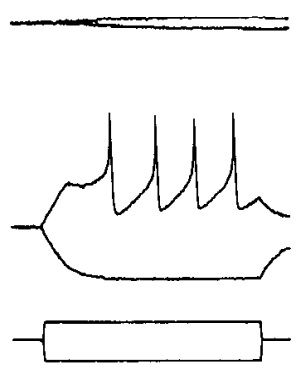

Figure 1. Comparison of electrical coupling at homo- and heteroganglionic synapses. The cells were current-clamped and one cell of a pair ( $V_{i}$; presynaptic cell) was injected with current $\left(I_{1}\right)$ while the change in membrane potential of the other, postsynaptic, cell $\left(V_{2}\right)$ was monitored. $A$, Pair of left upper quadrant neurons (LUQ; homoganglionic) from the abdominal ganglion separated by $100 \mu \mathrm{m}$ and clamped at $-70 \mathrm{mV}$; the coupling coefficient $(k)$ was 0.75 and the junctional conductance $\left(G_{j}\right)$ was $13 \mathrm{nS}$. Note that the electrotonic postsynaptic potentials (psps) elicited action potentials in the postsynaptic cell. $B$, Buccal-pleural pair (heteroganglionic: apposed somata with overlapping neurites) clamped at $-60 \mathrm{mV}$ and showing $k=0.25$ and $G_{j}=2 \mathrm{nS}$. Here, the psps (arrows) were not sufficient to evoke action potentials in the postsynaptic cell. $C$, Electrical coupling between a buccal cell $\left(V_{2}\right)$ and a bag cell $\left(V_{l}\right)$. The neurons, separated by $120 \mu \mathrm{m}$ and grown with hemolymph and without fetal calf serum, were current-clamped at $-60 \mathrm{mV}$ and the bag cell was injcetcd with current. $k=0.14$ and $G_{j}=1.3 \mathrm{nS}$. In all cases, reversing the role of pre- and postsynaptic cells gave the same result. Calibrations: $25 \mathrm{mV} ; 1 \mathrm{nA}(A, B) ; 2 \mathrm{nA}(C) ; 500 \mathrm{msec}(A) ; 250 \mathrm{msec}(B) ; 200 \mathrm{msec}(C)$.

pairs and extend the findings to heteroganglionic as well as other homoganglionic pairs.

Figure 2, $B, D$ shows that homoganglionic and heteroganglionic junctions are not uncoupled by either $1 \mathrm{~mm}$ octanol or heptanol, local anesthetics that uncouple cells of many other types (Johnston et al., 1980). This is consistent with a previous finding of resistance of buccal-buccal electrical synapses to these anesthetics (Bodmer et al., 1988). Thus, homoganglionic and heteroganglionic electrical synapses cannot be distinguished by any of the criteria we tested other than magnitude of junctional conductance.

\section{Modulation of heteroganglionic synapses by $\operatorname{Con} A$}

Although buccal cells and bag cells are not detectably coupled to one another when grown in the presence of serum, they are detectably coupled if cultured in the continual presence of serum and Con A (Lin and Levitan, 1987). This finding suggested that Con $\mathrm{A}$ is capable of changing the synaptic connectivity among these ncurons, either by promoting the establishment of new connections during synaptogenesis or by modulating the degree of coupling once electrical synapses are established. Since we found that buccal cells and bag cells can couple in culture when grown in the absence of serum and Con A (Fig. 1C), it appeared that the observed effect of Con A reflects changes in the magnitude of coupling rather than in the establishment of new connections. In order to further distinguish between thesc 2 possibilities, we exposed pairs of coupled neurons, grown in the absence of Con $\mathrm{A}$, to the lectin by adding it to the culture medium. Figure 3 shows that the junctional conductance of a heteroganglionic pair increases an order of magnitude within 10 hr of application of $100 \mathrm{~nm}$ Con A, while nonjunctional membrane currents are unaffected. The results of a series of similar experiments are summarized in Table 1 , which shows that the junctional conductances of coupled heteroganglionic pairs treat- ed with $100 \mathrm{~nm}$ Con A for 10-24 hr approach the level characteristic of untreated homoganglionic pairs.

The observed lectin-induced increase in electrical coupling was not due to inadequate space clamp or changes in voltagesensitive membrane currents since (1) $G_{j}$ was not changed by blocking voltage-sensitive membrane currents with $10 \mathrm{mM}$ TEA, $10 \mathrm{mM} \mathrm{Ba}^{2+}$ substituted for $\mathrm{Ca}^{2+}, 5 \mathrm{mM} \mathrm{Co}^{2+}$, and $10^{-5} \mathrm{M} \mathrm{TTX}$; (2) $G_{j}$ was the same whether determined directly under voltage clamp or calculated from current-clamp records; (3) $G_{j}$ was the same regardless of the member of the ccll pair used for current injection; and (4) $G_{j}$ was not dependent upon holding potential or command potential.

\section{Dynamics of modulation by Con $A$}

As a first step in investigating the mechanism by which Con $\mathrm{A}$ increases the electrical coupling of heteroganglionic pairs of neu-

\begin{tabular}{lllr}
\hline $\begin{array}{l}\text { Table 1. Synaptic specificity and modulation of junctional } \\
\text { conductance between cultured } \boldsymbol{A p l y s i a} \text { neurons }\end{array}$ \\
& & \multicolumn{1}{l}{$\boldsymbol{G}_{j}$} \\
Type of pair & Treatment & $n$ & $(\mathrm{nS})$ \\
\hline Homoganglionic & control & 25 & $14.7 \pm 3.3$ \\
Heteroganglionic & control & 26 & $3.3 \pm 0.8$ \\
Homoganglionic & Con A & 6 & $13.9 \pm 2.3$ \\
Heteroganglionic & Con A & 11 & $14.6 \pm 4.2$
\end{tabular}

$\overline{\text { Values are expressed as mean } \pm \text { SEM. Junctional conductance }\left(G_{j}\right) \text { was measured }}$ directly by voltage-clamping pairs of neurons that were either untreated (control) or incubated with $10^{-7} \mathrm{M}$ Con $\mathrm{A}$ for $10-24 \mathrm{hr}$. The different pairs of cells and numbers of pairs tested in each group were: homoganglionic, control: abdominal,

2 , bag cells, 6 , buccal, 8 , cerebral, 2 , pedal, 2, pleural, 5; heteroganglionic, control; bag-buccal, 6, bag-pleural, 3, buccal-pleural, 7, cerebral-pedal, 4, cerebral-pleural, 3, pedal-pleural, 3; homoganglionic, Con A: abdominal, 1, buccal, 4, pedal, 1; heteroganglionic, Con A: buccal-pleural, 3, cerebral-pleural, 8. Within each group, all combinations gave the same result, and thus the data are pooled in the body of the table. 
A

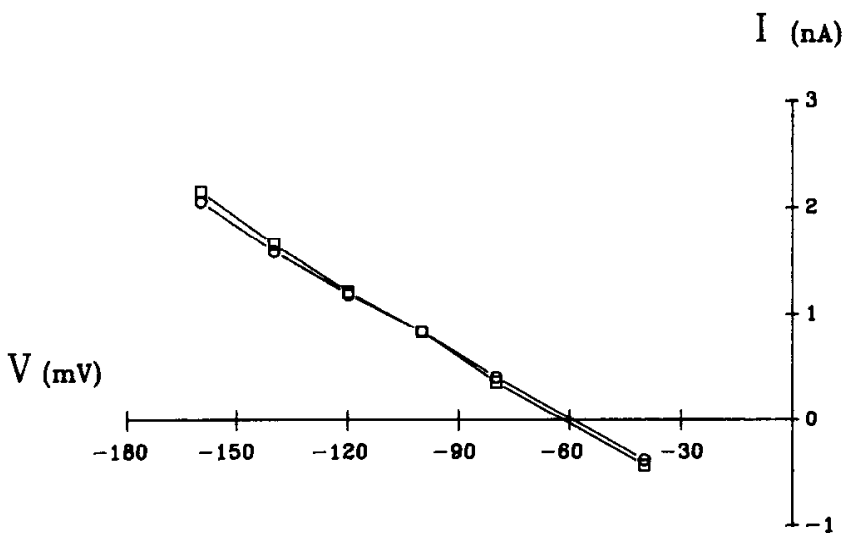

B

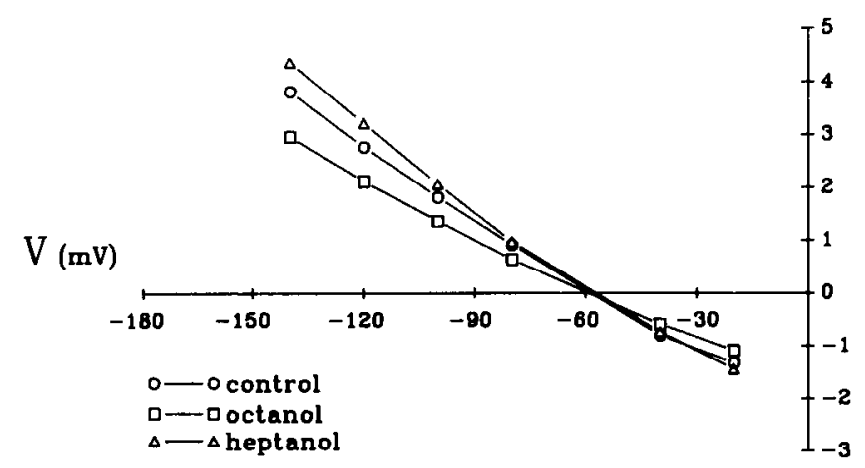

C

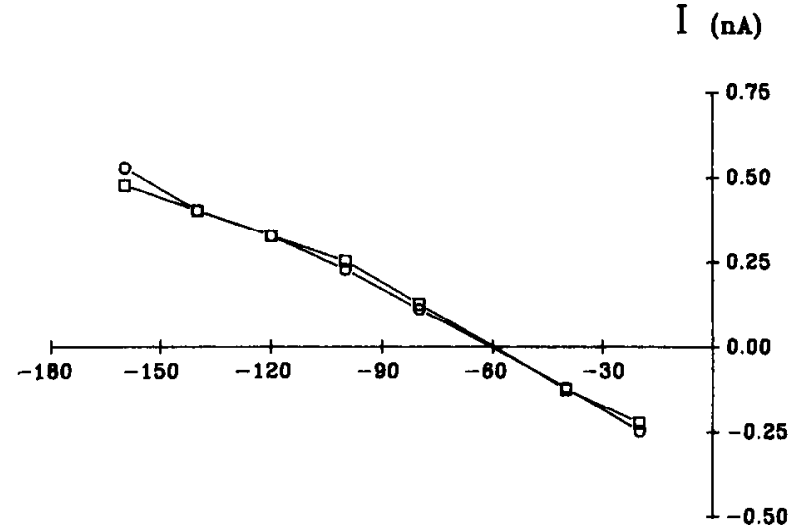

D

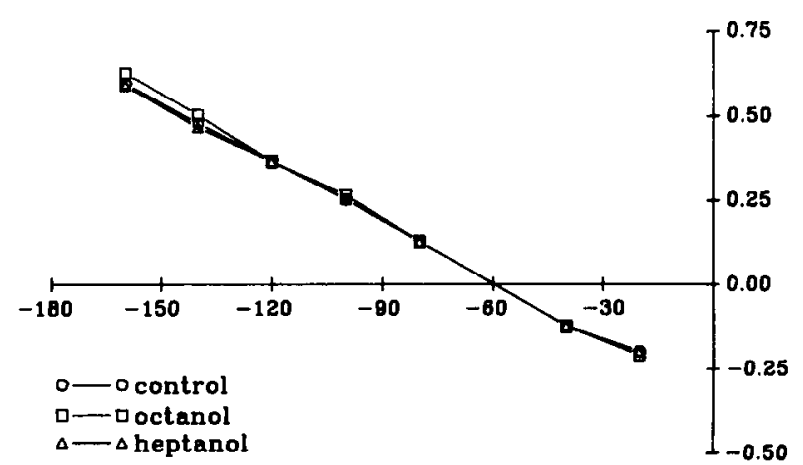

Figure 2. Properties of homo- and heteroganglionic synapses. $I-V$ curves for pairs of neurons voltage clamped at $-60 \mathrm{mV}$. $A$, Pair of apposed

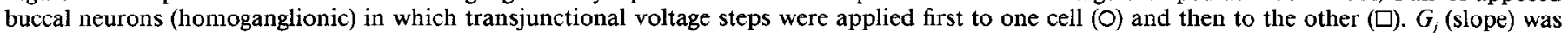

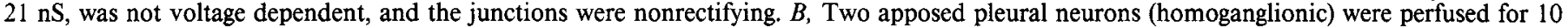

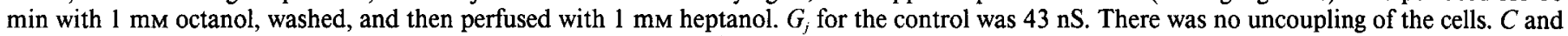

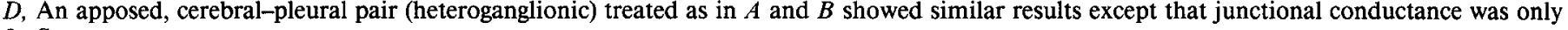
$5 \mathrm{nS}$.

rons, we exposed pairs of cells to bath applied Con A while chronically monitoring junctional conductance. Figure 4 illustrates the time course of an experiment with the cell pair of Figure 3. The junctional conductance begins to increase about $2 \mathrm{hr}$ after application of Con $\mathrm{A}$ and continues to increase for an additional $8 \mathrm{hr}$ even after removal of the Con $A$ from the perfusion medium. Figure 5 shows that there is no detectable elongation or retraction of neurites accompanying the change in $G_{j}$; thus, there is not a requirement for neurite outgrowth to form electrical synapses with high coupling coefficients, as appears to be the case for Helisoma neurons (Hadley et al., 1983). Moreover, Con A does not induce neurite outgrowth from neurons in established cultures, although it does in newly plated cells (Lin and Levitan, 1987).

By contrast, homoganglionic pairs of neurons that already have a relatively high junctional conductance do not show a significant change in coupling when treated similarly with Con A, as illustrated in Figure 6. In order to be certain that Con A had gained access to the cells in these cases, we made use of the observation by Kehoe (1978) that Con A rapidly induces a depolarizing reponse to L-glutamate in Aplysia neurons. As expected, Figure $7 A$ shows that there is no detectable response to L-glutamate prior to treatment with Con A. However, as shown in Figure $7 B$, within $0.5 \mathrm{hr}$ after initiating bath application of
Con A an inward current is elicited in response to a puff of L-glutamate, indicating that Con A does indeed have access to these homoganglionic pairs.

\section{Discussion}

We have found that Aplysia neurons grown in primary culture show specificity in the formation of electrical synapses that is detectable as a difference in synaptic efficacy. Pairs of neurons derived from the same ganglion, or homoganglionic pairs, form electrical connections with high coupling coefficients in culture. By contrast, pairs of neurons from different ganglia, or heteroganglionic pairs, form electrical connections with lower coupling coefficients. The different levels of coupling arise from differences in the magnitude of the macroscopic junctional conductance. Moreover, we have shown that synaptic efficacy can be altered in established synapses by the lectin, Con A, since it increases the macroscopic junctional conductance of heteroganglionic synapses to the level characteristic of homoganglionic synapses. When heteroganglionic pairs of neurons are grown in the absence of Con $A$ and later exposed to nanomolar concentrations of Con $A$, the junctional conductance increases within several hours after addition of the lectin. By contrast, the already high junctional conductance of homoganglionic synapses is not further increased by Con A. The long time course of the response 
A
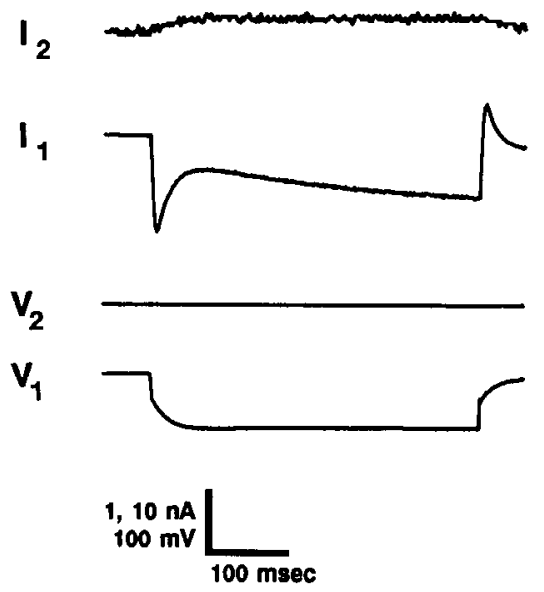

B
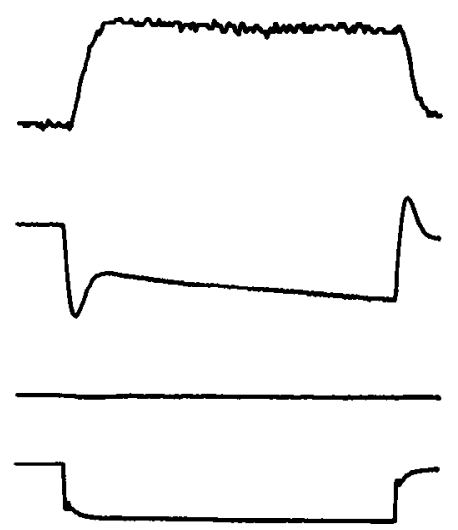

Figure 3. Modulation of junctional conductance by Con A. Voltage-clamp records for a buccal-pleural pair (heteroganglionic) held at $-70 \mathrm{mV}$. $A$, Voltage pulse applied to one cell $\left(V_{l}\right)$ activated nonjunctional membrane currents in that cell $\left(I_{l}\right)$; there was no change in holding potential of the postsynaptic cell $\left(V_{2}\right)$, and the resulting junctional current $\left(I_{2}\right)$ indicates a $G_{j}$ of $2 \mathrm{nS}$. B, After perfusion of the cells for $10.5 \mathrm{hr}$ with $10^{-7} \mathrm{M}$ Con $\mathrm{A}$, the junctional current $\left(I_{2}\right)$ had increased an order of magnitude, reflecting a $G_{j}$ of 18 $\mathrm{nS}$. The nonjunctional current $\left(I_{i}\right)$ was essentially unchanged, indicating no significant change in membrane input impedence. The voltage clamps were adjusted for stability at the expense of high-frequency response, and thus the voltage responses were relatively slow. to Con A suggests that protein synthesis might be involved, and preliminary data indicate that the modulation of junctional conductance by Con $\mathrm{A}$ is blocked by the protein synthesis inhibitor, anisomycin (Carrow and Levitan, 1988). It remains to be determined whether Con $A$ regulates the number of active gap junction channels, their unit conductance, or their open probability.

Previously, electrical coupling was not detected between buccal and bag neurons (a heteroganglionic combination) unless the cells were grown in the presence of Con A (Bodmer et al., 1984; Lin and Levitan, 1987). The relatively low level of coupling reported here for buccal-bag and other heteroganglionic pairs may have been unmasked by altered culture conditions; that is, in the present work, the neurons were cultured in the absence of fetal calf serum, a known inhibitor of electrical coupling between cultured sympathetic neurons (Higgins and Burton, 1982; Kessler et al., 1984). We have not investigated in detail the effects of serum on coupling between cultured Aplysia neurons.

Modulators that increase electrical or dye coupling in other systems include hormones (Radu et al., 1982; Kessler et al., 1984; Wolinsky et al., 1985), a catecholamine (Radu et al., 1982), cAMP and cAMP-dependent protein kinase (Flagg-Newton et al., 1981; Wiener and Loewenstein, 1983; Kessler et al., 1984; Saez et al., 1986), and glycoproteins and proteoglycans (Bargiello et al., 1987; Spray et al., 1987). In some cases, protein synthesis appears to be involved (Flagg-Newton et al., 1981; Spray et al., 1987).

The synaptic specificity described here as being reflected by synaptic efficacy is reminiscent of the specificity of electrical coupling in other systems. Thus, rabbit lens epithelial cells are electrically coupled to rat liver epithelia in vitro with lower coupling coefficients than the homotypic combinations (Michalke and Loewenstein, 1971). Rods in the tiger salamander retina are electrically coupled to neighboring cones less effectively than to neighboring rods (Attwell and Wilson, 1980). There are also cases in which electrical coupling is not detectable between heterotypic pairs of cells, even though the corresponding homotypic pairs are detectably coupled under the same culture conditions
(Gilula et al., 1972; Fentiman et al., 1976; Pitts and Burk, 1976; Bodmer et al., 1984; Lin and Levitan, 1987). Such specificity of electrical connections is not always the case, however. For example, rat ovarian granulosa cells show a high level of electrical coupling to mouse myocardial cells in mixed culture (Lawrence et al., 1978).

An analogous case of synaptic specificity among chemical synapses is the monosynaptic stretch reflex circuit of vertebrates. Stretch-sensitive sensory neurons make stronger synaptic connections with related (homonymous) motoneurons than with unrelated (heteronymous) motoneurons in the same region of the spinal cord (Scott and Mendell, 1976; Lichtman and Frank, 1984). This synaptic specificity, as for Aplysia neurons, is likely due to the specificity of cellular interactions during synaptogenesis (Nelson and Mendell, 1978; Lichtman et al., 1984).

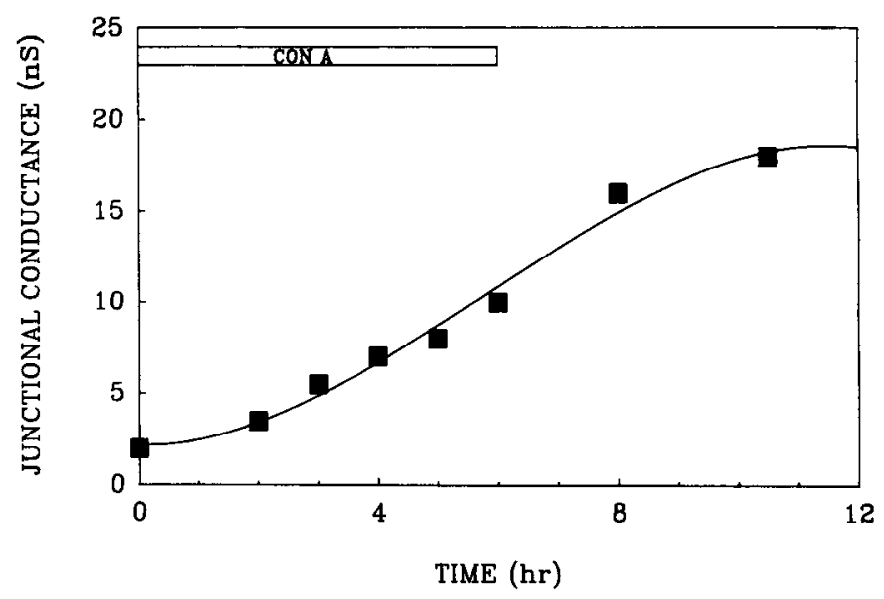

Figure 4. Time course of modulation of a heteroganglionic synapse by Con $A$. Junctional conductance for the buccal-pleural pair in Figure 3 as a function of time after starting bath application of Con A (at $t=$ 0 ). The $G_{j}$ increased an order of magnitude after perfusion with $10^{-7} \mathrm{M}$ Con A for the time indicated by the horizontal bar. The effect was not reversible with $4.5 \mathrm{hr}$ wash. The line indicates a third-order polynomial fitted to the data. 

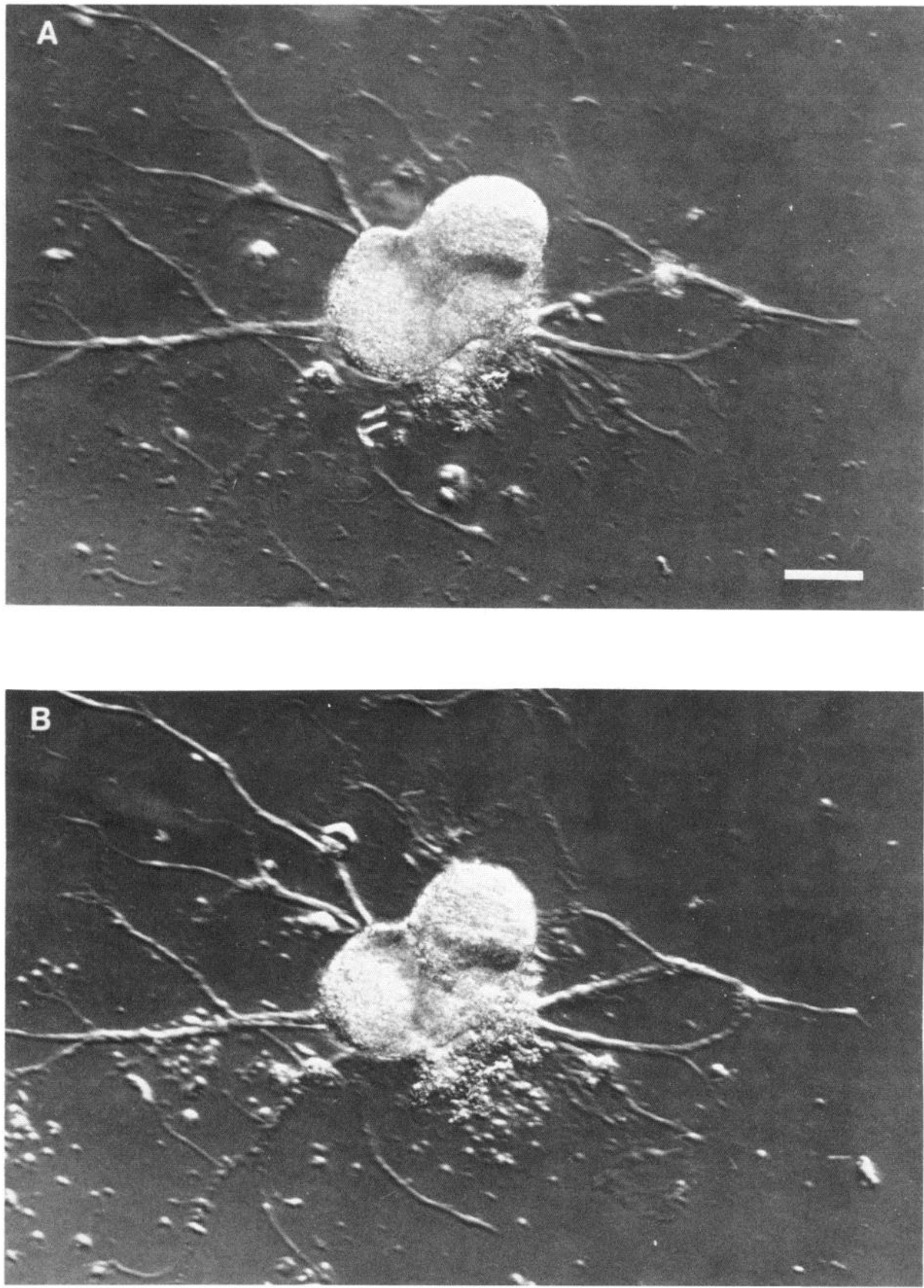

Figure 5. Con A modulation of electrical synapses is not accompanied by changes in neurite morphology. Light micrographs of the buccal-pleural pair from Figures 3 and 4. A, Before treatment; $B, 10.5 \mathrm{hr}$ after starting perfusion of Con A, there was no apparent extension or retraction of neurites. The slight distortion in one soma was likely due to the long-term electrode impalement. Scale bar, $50 \mu \mathrm{m}$. 


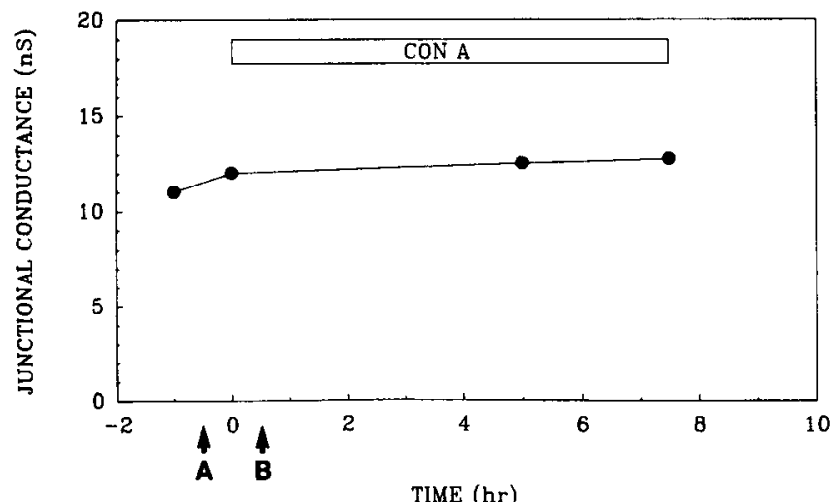

Figure 6. Con A does not modulate homoganglionic synapses. Cells were treated as described in Figure 5. Two apposed LUQ neurons showed no significant change in $G_{j}$ after treatment with $10^{-7} \mathrm{M}$ Con $\mathrm{A}$. The arrows below the abscissa refer to Figure 7.

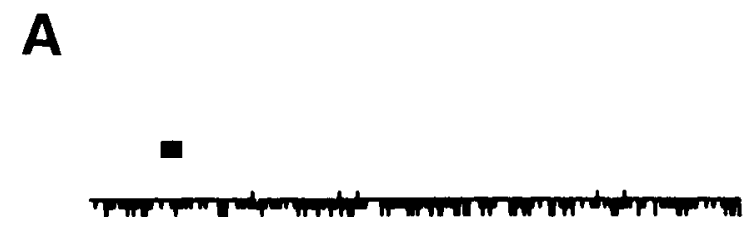

B
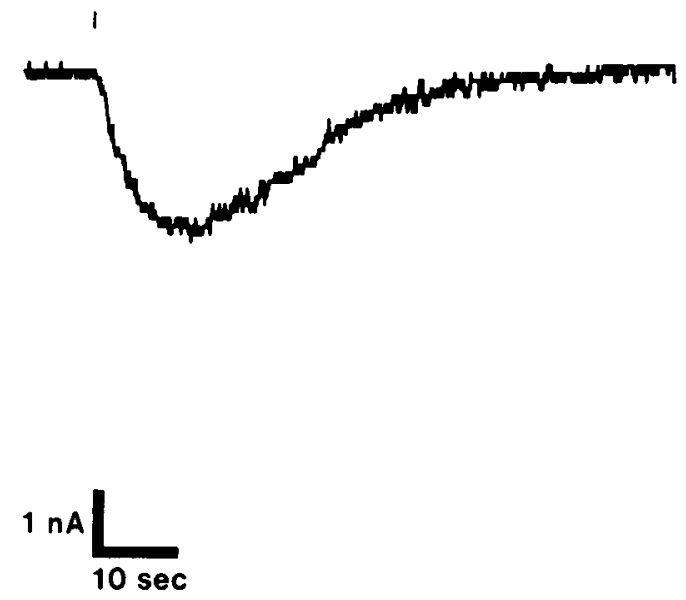

Figure 7. Con A induces a glutamate current even in the absence of synapse modulation. One of the LUQ neurons shown in Figure 6 was exposed to pressure ejection of $10^{-1} \mathrm{M} \mathrm{L}$-glutamate for the time indicated by the horizontal bars prior to $(A)$ and $30 \mathrm{~min}$ after $(B)$ bath application of Con A (see arrows under abscissa in Fig. 6). No current was elicited by L-glutamate before Con A treatment. However, after Con A treatment, an inward current was elicited by an even briefer puff of L-glutamate.
Whether the dichotomy in synaptic efficacy observed in vitro reflects the situation in vivo remains to be determined. The obscrvation of strong electrical coupling in vitro between ncurons with a common ganglionic origin is consistent with observations of intraganglionic electrical coupling (Gardner, 1971) and gap junction plaques (Kaczmarek et al., 1979) in vivo. By contrast, interganglionic electrical coupling has rarely been observed in Aplysia (Rayport and Kandel, 1980), although this might reflect the difficulty in detecting electrical coupling beiween cells separated by long connectives. Alternatively, the widespread electrical coupling observed in vitro between neurons from juveniles may be present in vivo only in juveniles; for example, medial cells in the pleural ganglion are coupled in vivo in juvenile Aplysia (unpublished observations), even though they have not been reported to be coupled in adults. Another possibility is that our observations in these regenerating neurons in culture reflect processes active during even earlier stages of development; for instance, differences in synaptic efficacy might be important for gangliogenesis. It is of interest in this regard that communication compartments of dye coupled cells correlate with developmental compartments in a number of systems (Caveney, 1985).

Regardless of the situation in vivo, these neurons are capable of distinguishing homoganglionic from heteroganglionic partners in vitro. This cell-cell interaction is likely mediated by ganglion-specific cell-recognition molecules. Furthermore, regulation of connectivity by Con A suggests that these cell-recognition molecules are, or are closely associated with, lectin receptors. Other evidence that lectins and lectin receptors may be involved in cell recognition in the nervous system comes from the observation that monoclonal antibodies to lactosebinding lectins label the same subsets of dorsal root ganglion neurons that express their complementary oligosaccharide ligands (Regan et al., 1986). Determination of the mechanisms by which the synapses described here are specified and modified would provide insights into problems of cell-cell recognition during synaptogenesis. The ability to quantify and modulate electrical coupling in this system should facilitate study of this and other problems of connectivity.

\section{References}

Arechiga, H., M. Chiquet, D. P. Kuffler, and J. G. Nicholls (1986) Formation of specific connections in culture by identified leech neurones containing serotonin, acetylcholine and peptide transmitters. J. Exp. Biol. 126: 15-31.

Attwell, D., and M. Wilson (1980) Behaviour of the rod network in the tiger salamander retina mediated by membrane properties of individual rods. J. Physiol. (Lond.) 309: 287-315.

Bargiello, T. A., L. Saez, M. K. Baylies, G. Gasic, M. W. Young, and D.C. Spray (1987) The Drosophila clock gene per affects intercellular junctional communication. Nature 328: 686-691.

Bennett, M. V. L. (1966) Physiology of electrotonic junctions. Ann. NY Acad. Sci. 137: 509-539.

Bodmer, R., D. Dagan, and I. B. Levitan (1984) Chemical and electrotonic connections between Aplysia neurons in primary culture. J. Neurosci. 4: 228-233.

Bodmer, R., V. Verselis, I. B. Levitan, and D. C. Spray (1988) Electrotonic synapses between Aplysia neurons in situ and in culture: Aspects of regulation and measurements of permeability. J. Neurosci. 8: $1656-1670$

Camardo, J., E. Proshansky, and S. Schacher (1983) Identified Aplysia neurons form specific chemical synapses in culture. J. Neurosci. 3: 2614-2620.

Carrow, G. M., and I. B. Levitan (1987) Selective synaptogenesis and 
modulation of junctional conductance in cultured neurons of Aplysia. Soc. Neurosci. Abstr. 13: 1455.

Carrow, G. M., and I. B. Levitan (1988) Receptor-mediated regulation of synaptic connectivity in cultured Aplysia neurons. Soc. Neurosci. Abstr. 14: 895.

Caveney, S. (1985) The role of gap junctions in development. Annu. Rcy. Physiol. 47: 319-335.

Chiquet, M., and S. E. Acklin (1986) Attachment to Con A or extracellular matrix initiates rapid sprouting by cultured leech neurons. Proc. Natl. Acad. Sci. USA 83: 6188-6192.

Cotman, C. W., and D. T. Monaghan (1988) Excitatory amino acid neurotransmission: NMDA receptors and Hebb-type synaptic plasticity. Annu. Rev. Neurosci. 11:61-80.

Dagan, D., and I. B. Levitan (1981) Isolated identified Aplysia neurons in cell culture. J. Neurosci. 7: 736-740.

DeGeorge, J. J., N. Slepecky, and S. Carbonetto (1985) Concanavalin A stimulates neuron-substratum adhesion and nerve fiber outgrowth in culture. Dev. Biol. 111: 335-351.

Edelman, G. M. (1986) Cell adhesion molecules in neural histogenesis. Annu. Rev. Physiol. 48: 417-430.

Fentiman, I., J. Taylor-Papadimitriou, and M. Stoker (1976) Selective contact-dependent communication. Nature 264: 760-762.

Flagg-Newton, J. L., G. Dahl, and W. R. Loewenstein (1981) Cell junction and cyclic AMP: I. Upregulation of junctional membrane permeability and junctional membrane particles by administration of cyclic nucleotide or phosphodiesterase inhibitor. J. Membr. Biol. 63: $105-121$.

Fuchs, P. A., J. G. Nicholls, and D. F. Ready (1981) Membrane properties and selective connexions of identified leech neurones in culture. J. Physiol. (Lond.) 316: 203-223.

Gardner, D. (1971) Bilateral symmetry and interneuronal organization in the buccal ganglia of Aplysia. Science 17.3:550-553.

Gilula, N. B., O. R. Reeves, and A. Steinbach (1972) Metabolic coupling, ionic coupling and cell contacts. Nature 235: 262-265.

Goodman, C. S., J. A. Raper, R. K. Ho, and S. Chang (1982) Pathfinding by neuronal growth cones in grasshopper embryos. Symp. Soc. Dev. Biol. 40: 275-316.

Hadley, R. D., S. B. Kaler, and C. S. Cohan (1983) Electrical synapse formation depends on interaction of mutually growing neurites. Science 221: 466-468.

Haydon, P. G. (1988) The formation of chemical synapses between cell-cultured neuronal somata. J. Neurosci. 8: 1032-1038.

Higgins, D., and H. Burton (1982) Electrotonic synapses are formed by fetal-rat sympathetic neurons maintained in a chemically-defined culture medium. Neuroscience 7: 2241-2253.

Jessell, T. M. (1988) Adhesion molecules and the hierarchy of neural development. Neuron $1: 3-13$.

Johnston, M. F., S. A. Simon, and F. Ramon (1980) Interaction of anaesthetics with electrical synapses. Nature 286: 498-500.

Kaczmarek, L. K., M. Finbow, J. P. Revel, and F. Strumwasser (1979) The morphology and coupling of Aplysia bag cells within the abdominal ganglion and in cell culture. J. Neurobiol. 10: 535-550.

Kandel, E. R., and J. H. Schwartz (1982) Molecular biology of learning: Modulation of transmitter release. Science 218: 433-443.

Kehoe, J.S. (1978) Transformation by concanavalin A of the response of molluscan neurones to L-glutamate. Nature 274: 866-869.

Kessler, J. A., D. C. Spray, J. C. Saez, and M. V. L. Bennett (1984) Determination of synaptic phenotype: Insulin and cAMP independently initiate development of electrotonic coupling between cultured sympathetic neurons. Proc. Natl. Acad. Sci. USA 81: 6235-6239.

Lawrence, T. S., W. H. Beers, and N. B. Gilula (1978) Transmission of hormonal stimulation by cell-to-cell communication. Nature 272: $501-506$.

Levitan, I. B. (1988) Modulation of ion channels in neurons and other cells. Annu. Rev. Neurosci. 11: 119-136.
Lichtman, J. W., and E. Frank (1984) Physiological evidence for specificity of synaptic connections between individual sensory and motor neurons in the brachial spinal cord of the bullfrog. J. Neurosci. 4: 1745-1753.

Lichtman, J. W., S. Jhaveri, and E. Frank (1984) Anatomical basis of specific connections between sensory axons and motor neurons in the brachial spinal cord of the bullfrog. J. Neurosci. 4: 1754-1763.

Lin, S., and I. B. Levitan (1987) Concanavalin A alters synaptic specificity between cultured Aplysia neurons. Science 237: 648-650.

McKay, R. D. G., S. Hockfield, J. Johansen, I. Thompson, and K. Frederiksen (1983) Surface molecules identify groups of growing axons. Science 222: 788-794.

Michalke, W., and W. R. Loewenstein (1971) Communication between cells of different type. Nature 232: 121-122.

Nelson, S. G., and L. M. Mendell (1978) Projection of single knee flexor Ia fibers to homonymous and heteronymous motoneurons. J. Neurophysiol. 41: 778-787.

Nicoll, R. A.., J. A. Kauer, and R. C. Malenka (1988) The current excitement in long-term potentiation. Neuron 1:97-103.

$\mathrm{Nja}, \mathrm{A}$., and D. Purves (1977) Specific innervation of guinea-pig superior cervical ganglion cells by preganglionic fibres arising from different levels of the spinal cord. J. Physiol. (Lond.) 264: 565-583.

Pitts, J. D., and R. R. Burk (1976) Specificity of junctional communication between animal cells. Nature 264: 762-764.

Radu, A., G. Dahl, and W. R. Loewenstein (1982) Hormonal regulation of cell junction permeability: Upregulation by catecholamine and prostaglandin E. J. Membr. Biol. 70: 239-251.

Rayport, S. G., and E. R. Kandel (1980) Developmental modulation of an identified electrical synapse: Functional uncoupling. J. Neurophysiol. 3: 555-567.

Rayport, S. G., and S. Schacher (1986) Synaptic plasticity in vitro: Cell culture of identified Aplysia neurons mediating short-term habituation and sensitization. J. Neurosci. 6: 759-763.

Regan, L. J., J. Dodd, S. H. Barondes, and T. M. Jessell (1986) Selective expression of endogenous lactose-binding lectins and lactoseries glycoconjugates in subsets of rat sensory neurons. Proc. Natl. Acad. Sci. USA 83: 2248-2252.

Rutishauser, U., A. Acheson, A. K. Hall, D. M. Mann, and J. Sunshine (1988) The neural cell adhesion molecule (NCAM) as a regulator of cell-cell interactions. Science 240: 53-57.

Saez, J. C., D. C. Spray, A. C. Nairn, E. Hertzberg, P. Greengard, and M. V. L. Bennett (1986) cAMP increases junctional conductance and stimulates phosphorylation of the $27-\mathrm{kDa}$ principal gap junction polypeptide. Proc. Natl. Acad. Sci. USA 83: 2473-2477.

Schacher, S., and E. Proshansky (1983) Neurite regeneration by Aplysia neurons in dissociated cell culture: Modulation by Aplysia hemolymph and the presence of the initial axonal segment. J. Neurosci. 3: 2403-2413.

Scott, J. G., and L. M. Mendell (1976) Individual EPSPs produced by single triceps surae Ia afferent fibers in homonymous and heteronymous motoneurons. J. Neurophysiol. 39: 679-692.

Spray, D. C., M. Fujita, J. C. Saez, H. Choi, T. Watanabe, E. Hertzberg, L. C. Rosenberg, and L. M. Reid (1987) Proteoglycans and glycosaminoglycans induce gap junction synthesis and function in primary liver cultures. J. Cell Biol. 105: 54l-551.

Thoenen, H., and D. Edgar (1985) Neurotrophic factors. Science 229: 238-242.

Wiener, E. C., and W. R. Loewenstein (1983) Correction of cell-cell communication defect by introduction of a protein kinase into mutant cells. Nature 305: 433-435.

Wolinsky, E. J., P. H. Patterson, and A. L. Willard (1985) Insulin promotes electrical coupling between cultured sympathetic neurons. J. Neurosci. 5: 1675-1679. 